Proceedings of the 17th Czech and Slovak Conference on Magnetism, Košice, Slovakia, June 3-7, 2019

\title{
Shaped Crystal Growth of Fe-Al Alloy Plates by Micro Pulling down Method
}

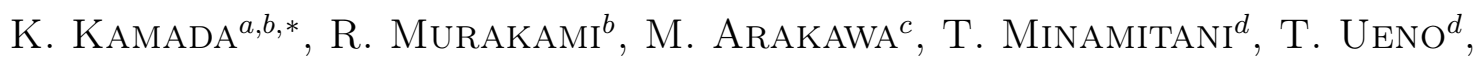 \\ Y. Shoji ${ }^{b, e}$, A. YAmaji ${ }^{e}$, M. Yoshino ${ }^{b, e}$, S. Kurosawa ${ }^{a, e}$, Y. Yokota $^{a}$, \\ Y. OHASHI ${ }^{e}$, V.V. Kochurikhin ${ }^{f}$ AND A. YoshikaWA ${ }^{a, b, e}$ \\ ${ }^{a}$ New Industry Creation Hatchery Center, Tohoku University, Sendai, 980-8577, Japan \\ ${ }^{b} \mathrm{C} \&$ A Corporation, Sendai, 980-8579, Japan \\ ${ }^{c}$ Graduate School of Biomedical Engineering, Tohoku University, Sendai, 980-8577, Japan \\ ${ }^{d}$ Kanazawa University, Kanazawa, 920-1192, Japan \\ ${ }^{e}$ Institute for Materials Research, Tohoku University, Sendai, 980-8577, Japan \\ ${ }^{f}$ General Physics InstituteRussian Academy of Sciences, 38 Vavilov Str., 119991 Moscow, Russia
}

Plate shaped $\mathrm{Fe}-\mathrm{Al}$ alloy crystals were successfully grown using the $\mu$-PD method. The orientation and grain size could be controlled by using the well oriented $\mathrm{Fe}_{0.95} \mathrm{Al}_{0.05}$ seed crystal. The as-grown $\mathrm{Fe}_{0.82} \mathrm{Al}_{0.18}$ and $\mathrm{Fe}_{0.80} \mathrm{Al}_{0.20}$ showed the magnetostriction $3 / 2 \lambda=121$ and $149 \mathrm{ppm}$, respectively, which is comparable to the values for single crystal samples grown by the Bridgman-Stockbarger method. Distributions of $\mathrm{Fe}$ and $\mathrm{Al}$ were homogenous along the growth direction within standard deviations of $0.35 \%$ and $1.3 \%$, respectively. A prototype vibration energy harvester was demonstrated using the grown $\mathrm{Fe}-\mathrm{Al}$ alloys.

DOI: 10.12693/APhysPolA.137.1009

PACS/topics: $\mu$-PD method, crystal growth, Fe-Al alloy, magnetostriction, vibration energy harvester

\section{Introduction}

Conversion technique of mechanical vibration energy into electrical energy using magnetostrictive materials have attracted to attention in energy harvesting applications. Among the magnetostrictive materials the $\mathrm{Fe}-\mathrm{Ga}[1-5]$ and $\mathrm{Fe}-\mathrm{Al}$ alloys $[3,6,7]$ are found attractive mainly due to advantages in terms of price, mechanical strength, and high magnetostriction constant. Up to now, bulk crystals of $\mathrm{Fe}-\mathrm{Ga}$ alloy have been produced by the Bridgman-Stockbarger (BS) method [8-10], or the Czochralski $(\mathrm{Cz})$ method $[4,11]$. Using these methods, a big bulk crystal up to $2 \sim 3$ inch diameter can be grown. Especially $\mathrm{Fe}-\mathrm{Al}$ has lower magnetostriction $3 / 2 \lambda$ than $\mathrm{Fe}-\mathrm{Ga}$, but does not contain rare metal. $\mathrm{Fe}-\mathrm{Al}$ has a high advantage in terms of price of raw materials for its mass production.

However, uniformity of chemical composition along the crystal growth direction can not be avoided due to the segregation in these alloys by the BS and $\mathrm{Cz}$ method. This results in uniformity of magnetostriction constant and reduction of the production efficiency. The micro pulling down $\mu$-PD method has been developed as a shaped crystal growth technique. Our group have reported shaped crystal growth of oxide and fluoride single crystals with different shape such as rod, plate tube, thin fiber, etc. Advantages of this method is low segregation due to high growth rate and small diffusion of melt

\footnotetext{
* corresponding author
}

at the solid-liquid interface, and small kerf loss due to near net shape crystal $[5,12,13]$. In this study we report the shaped long plate crystal growth of $\mathrm{Fe}-\mathrm{Al}$ alloys using the $\mu$-PD method. Chemical composition analysis and magnetostrictive properties are evaluated comparing with a commercially available $\mathrm{Fe}-\mathrm{Ga}$ alloy grown by the $\mathrm{Cz}$ method. A prototype vibration energy harvester using the grown $\mathrm{Fe}-\mathrm{Al}$ alloy was demonstrated.

\section{Experimental procedure}

Plate shaped $\mathrm{Fe}-\mathrm{Ga}$ alloy crystals were grown by the $\mu$-PD method using high-frequency induction heating under $\mathrm{Ar}+1 \% \mathrm{H}_{2}$ atmosphere. High purity $\mathrm{Fe}$ and $\mathrm{Al}$ powders $(4 \mathrm{~N})$ were used as a starting material and they were set into an alumina crucible with a hole of $1 \times 7 \mathrm{~mm}^{2}$ size opening at the bottom. The ingots were directly heated by the HF induction coil up to the melting point of each $\mathrm{Fe}-\mathrm{Al}$ alloys. After the raw materials were completely melted, a seed plate was immersed into the opening and brought into physical contact with the melt in the crucible. The pulling down rate were $0.3 \mathrm{~mm} / \mathrm{min}$. Details of crystal growth procedure was described in previous reports $[5,14]$. Scanning electron microscope (SEM) observation with an energy dispersive X-ray spectrometry (EDX) detector was performed using a fieldemission SEM (FE-SEM, JSM7800-F, JEOL) to observe chemical composition along the growth direction. Electron back scatter diffraction (EBSD) measurements were performed to investigate the crystal orientations with a step size of 1 to $2 \mu \mathrm{m}$. INCA software was used for 
the orientation measurement and analysis. EBSD was conducted at $15 \mathrm{kV}$. The magnetostriction was measured by attaching a strain gauge, and applying magnetic field of up to \pm 2000 Oe parallel and perpendicular to the crystal growth direction.

\section{Results and discussion}

At the beginning of this study, we tried to grow oriented $\mathrm{Fe}_{0.95} \mathrm{Al}_{0.05}$ alloy crystals by using a polycrystalline iron plate because $\mathrm{Fe}-\mathrm{Al}$ alloy crystals are not marketed. $\mathrm{Fe}_{0.95} \mathrm{Al}_{0.05}$ can be used as a seed for growth of $\mathrm{Fe}_{0.82} \mathrm{Al}_{0.18}$, as their melting points are close, without the low temperature phase transition.

Figure 1 (top) shows the result of the second trial of $\mathrm{Fe}_{0.95} \mathrm{Al}_{0.05}$ alloy crystal growth by the shape controlled $\mu$-PD method. The growth rate was $0.3 \mathrm{~mm} / \mathrm{min}$. The grown plate was shaped with a cross section of $1 \times 5 \mathrm{~mm}^{2}$ size and $62 \mathrm{~mm}$ length. Figure 1 (bottom) show inverse pole figure (IPF) images of the first and second trials of $\mathrm{Fe}_{0.95} \mathrm{Al}_{0.05}$ in parallel direction of crystal growth. The images focus near $30 \mathrm{~mm}$ growth position of a plate-shaped crystal. The grown crystals showed single domain within the field of measurement even in the first trial. Optimized growth condition identical to what was reported previously for $\mathrm{Fe}-\mathrm{Ga}$ alloy was applied for this $\mathrm{Fe}_{0.95} \mathrm{Al}_{0.05}$ alloy crystal growth. It is thought that the optimized growth condition promoted the stable crystal growth and expansion of grain size. The measured disorientations from $\langle 100\rangle$ of body centered cubic structure for the 1st trial was around less than around $23.7^{\circ}$. The grown crystal of first trial was used as a seed for the 2 nd trial. The grown crystal of first trial was cut and polished along $\langle 100\rangle$ orientation. The measured misorientations from $\langle 100\rangle$ for the second trial was around $10.5^{\circ}$. Finally, we could prepare several plates of $\mathrm{Fe}_{0.95} \mathrm{Al}_{0.05}$ alloy crystals as seeds for $\mathrm{Fe}_{0.82} \mathrm{Al}_{0.18}$ crystal growth.
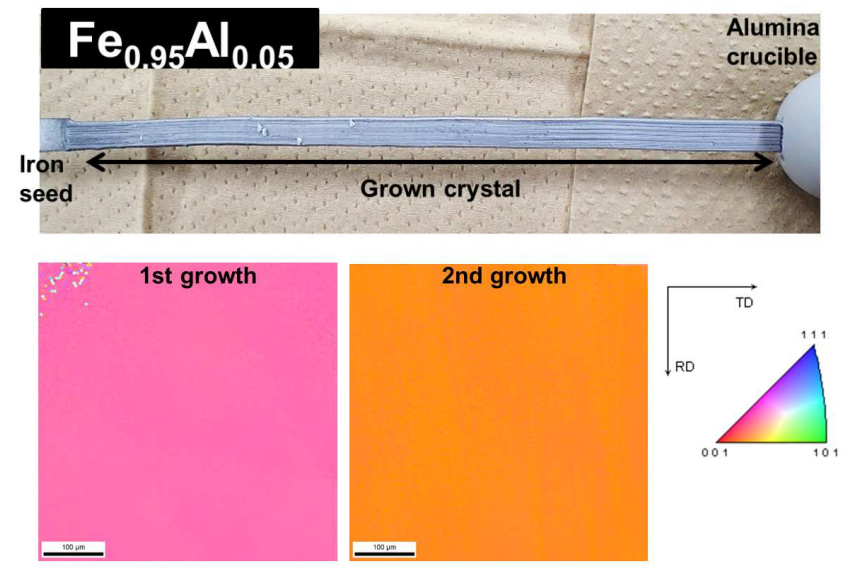

Fig. 1. As-grown $\mathrm{Fe}_{0.95} \mathrm{Al}_{0.05}$ alloy crystal grown by the $\mu$-PD method (top), and IPF images of perpendicular plane to the pulling down direction of $\mu$-PD (bottom).
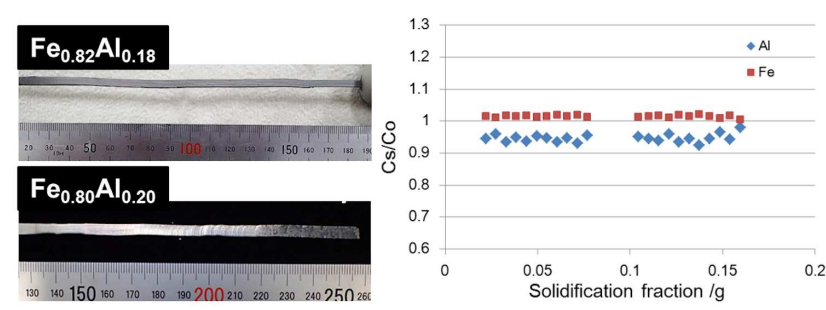

Fig. 2. As-grown $\mathrm{Fe}_{0.82} \mathrm{Al}_{0.18}$ and $\mathrm{Fe}_{0.80} \mathrm{Al}_{0.20}$ alloy crystals grown by the $\mu$-PD method using the $\mathrm{Fe}_{0.95} \mathrm{Al}_{0.05}$ seeds (left), and the composition distribution in along the growth direction in the $\mathrm{Fe}_{0.80} \mathrm{Al}_{0.20}$ alloy crystal (right).

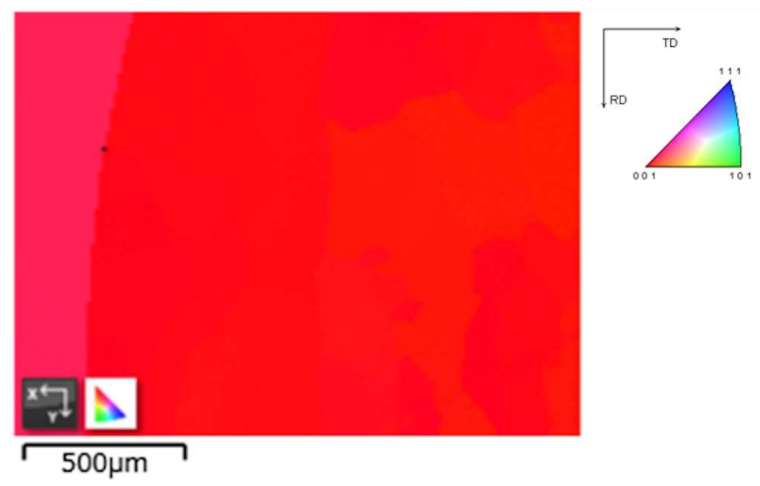

Fig. 3. The IPF image of perpendicular plane to the pulling down direction of the $\mathrm{Fe}_{0.82} \mathrm{Al}_{0.18}$ alloy crystal.

Figure 2 (left) shows the as-grown $\mathrm{Fe}_{0.82} \mathrm{Al}_{0.18}$ and $\mathrm{Fe}_{0.80} \mathrm{Al}_{0.20}$ alloy crystals grown by the $\mu$-PD method using the $\mathrm{Fe}_{0.95} \mathrm{Al}_{0.05}$ seed. The growth rate was $0.3 \mathrm{~mm} / \mathrm{min}$. The growth plates were shaped with a cross section of $1 \times 5 \mathrm{~mm}^{2}$ size, $160 \mathrm{~mm}$ and $125 \mathrm{~mm}$ length for $\mathrm{Fe}_{0.82} \mathrm{Al}_{0.18}$ and $\mathrm{Fe}_{0.80} \mathrm{Al}_{0.20}$ alloy, respectively. The composition distribution along the growth direction of the $\mathrm{Fe}_{0.80} \mathrm{Al}_{0.20}$ alloy crystal is shown in Fig. 2 (right). The solidification fraction (g) was about 0.16 . The effective segregation coefficient of $\mathrm{Fe}$ and $\mathrm{Al}$ showed $k_{\text {eff }}=1.02$ and 0.942 , respectively. Actual average chemical composition of the grown $\mathrm{Fe}_{0.80} \mathrm{Al}_{0.20}$ alloy was around 81.2 at.\% for Fe and 18.8 at.\% for Al. Distributions of $\mathrm{Fe}$ and $\mathrm{Al}$ were homogeneous along the growth direction within standard deviations of $0.35 \%$ and $1.3 \%$, respectively. Observed homogeneity is better than that of $\mathrm{Fe}-\mathrm{Ga}$ alloy grown by the $\mathrm{Cz}[4]$ and $\mu$-PD method [5]. In the case of $\mathrm{Fe}-\mathrm{Al}$, the linearity between solid line and liquid line in the phase diagram is much closer compared to $\mathrm{Fe}-\mathrm{Ga}$. This is one of the reason of the homogeneity. Figure 3 shows inverse pole figure images of the $\mathrm{Fe}_{0.82} \mathrm{Al}_{0.18}$ in parallel direction of crystal growth. The image focuses near the $80 \mathrm{~mm}$ growth position of a plate-shaped crystal. The measured misorientation of the main grain from $\langle 100\rangle$ was around less than $3.5^{\circ}$. The plate shaped $\mathrm{Fe}_{0.82} \mathrm{Al}_{0.18}$ and $\mathrm{Fe}_{0.80} \mathrm{Al}_{0.20}$ alloy crystals, oriented much close to $\langle 100\rangle$ direction, were successfully grown by using the oriented $\mathrm{Fe}_{0.95} \mathrm{Al}_{0.05}$ seeds. 

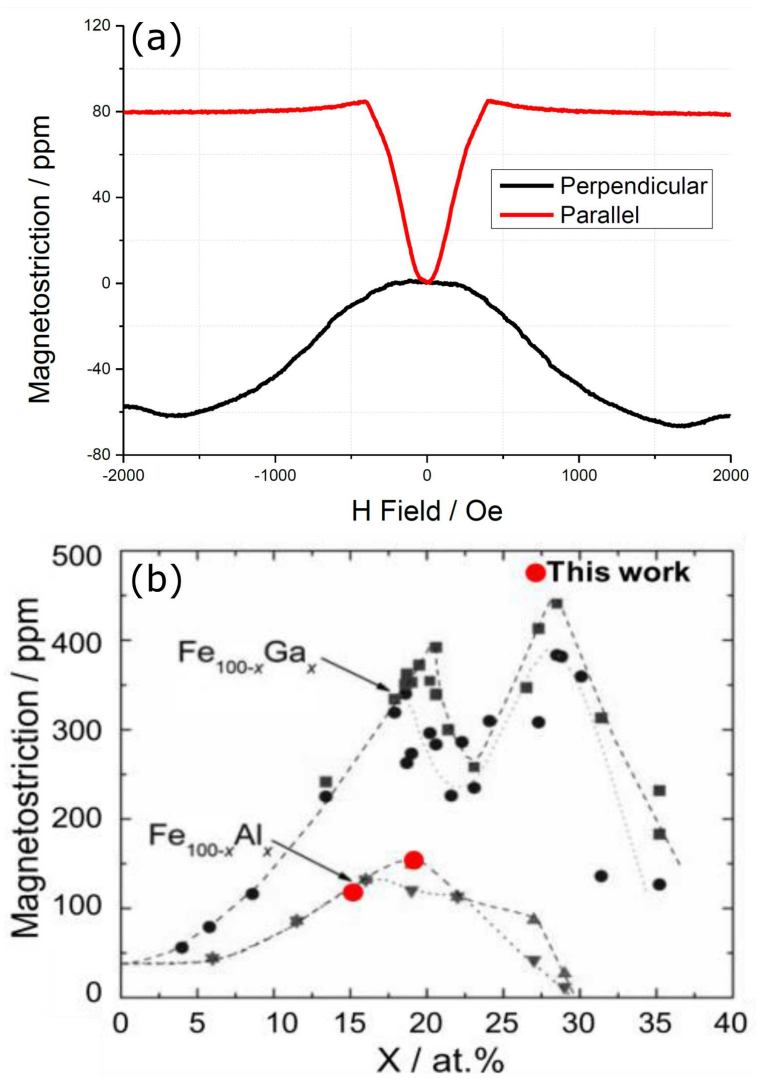

Fig. 4. Magnetic field dependence of magnetostriction in the $\langle 100\rangle$ crystal growth direction for the plateshaped $\mathrm{Fe}_{0.80} \mathrm{Al}_{0.20}$ grown by the $\mu$-PD method (a), and magnetostriction $3 / 2 \lambda$ of $\mathrm{Fe}-\mathrm{Al}$ alloys as a function of $\mathrm{Al}$ concentration (b). The $\mu$-PD samples are plotted as red circles on the graph in [7].

The magnetostrictive property was investigated by applying the magnetic field parallel $(\|)$ and perpendicular $(\perp)$ to the measuring samples. Figure 4 shows that magnetostrictive property of the $\mathrm{Fe}_{0.80} \mathrm{Al}_{0.20}$ sample in the growth direction depends on the magnetic field. From the difference between the saturation magnetostriction of parallel and perpendicular measurements, the value of $3 / 2 \lambda$ for the sample was evaluated to be $\approx 149 \mathrm{ppm}$, (Fig. 5). The $\mathrm{Fe}_{0.82} \mathrm{Al}_{0.18}$ sample yielded $121 \mathrm{ppm}$ for the same measurement set-up. This value is fully comparable to $\mathrm{Fe}-\mathrm{Al}$ single crystal grown by the $\mathrm{BS}$ method [7]. It was evident that plate shaped $\mathrm{Fe}-\mathrm{Al}$ crystals grown by $\mu$-PD method can posses almost the same magnetostriction as single crystal alloy. To evaluate the potential for vibration energy harvester, a prototype was made using the $\mathrm{Fe}-\mathrm{Al}$ alloy samples. An as-grown $\mathrm{Fe}-\mathrm{Ga}$ alloy was machined to the size of $4 \times 0.7 \times 14.8 \mathrm{~mm}^{3}$. A copper coil was wound with 3655 turns around the $\mathrm{Fe}-\mathrm{Al}$ alloys. The prototype was set to a vibration generator and vibrated at an effective vibration acceleration of $0.1 \mathrm{G}_{\mathrm{rms}}$. A photograph of the prototype and time response of open-circuit voltage $\left(V_{o p}\right)$ is shown in Fig. 5 (bottom). The maximum voltage of 0.046 and $0.096 \mathrm{~V}$ was observed using the $\mathrm{Fe}_{0.82} \mathrm{Al}_{0.18}$ and $\mathrm{Fe}_{0.80} \mathrm{Al}_{0.20}$ alloy
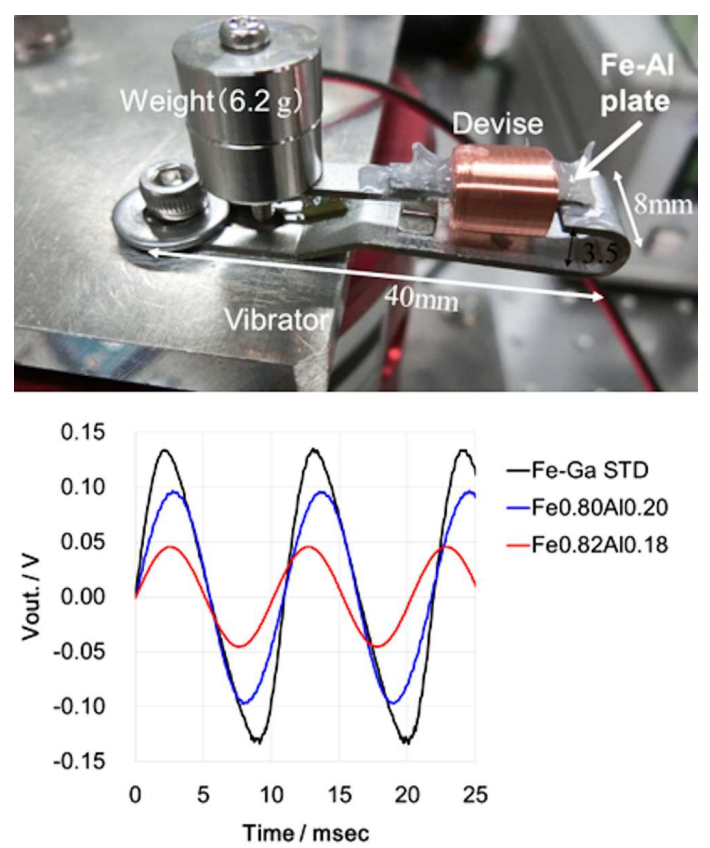

Fig. 5. Photograph of the prototype (top), and time response of open-circuit voltage $\left(V_{o p}\right)$ for the prototype device using the plate-shaped $\mathrm{Fe}-\mathrm{Al}$ alloys (bootom).

samples, respectively. The same examination was performed on a device using commercially available Fe- $\mathrm{Ga}$ alloys (Galfenol) grown by the $\mathrm{CZ}$ method. The $\mathrm{Fe}-\mathrm{Ga}$ standard has around $300 \mathrm{ppm}$ of $3 / 2 \lambda$ value. The maximum voltage was $0.135 \mathrm{~V}$ for the Galfenol device. The correlation between magnetstriction of alloys and generated voltage in the energy harvester was confirmed. Fe$\mathrm{Al}$ is highly advantageous in terms of not using rare metals and the cost of raw materials. Although, $\mathrm{Fe}_{0.80} \mathrm{Al}_{0.20}$ showed almost half of magnetstriction and $70 \%$ of voltage generation compared to the Galfenol standard.

\section{Conclusion}

Plate shaped $\mathrm{Fe}-\mathrm{Al}$ alloy crystals were successfully grown using the $\mu$-PD method. At the beginning of this work $\mathrm{Fe}_{0.95} \mathrm{Al}_{0.05}$ seed crystals with good orientation were tried to be grown by using polycrystalline iron plate. The orientation and grain size could be controlled by using the well oriented $\mathrm{Fe}_{0.95} \mathrm{Al}_{0.05}$ seed crystal. The as-grown $\mathrm{Fe}_{0.82} \mathrm{Al}_{0.18}$ and $\mathrm{Fe}_{0.80} \mathrm{Al}_{0.20}$ shown the magnetostriction $3 / 2 \lambda=121$ and $149 \mathrm{ppm}$, respectively, which is comparable value to single crystal samples grown by the BS method. Fe- $\mathrm{Al}$ is highly advantageous in terms of not using rare metals and the cost of raw materials though $\mathrm{Fe}_{0.80} \mathrm{Al}_{0.20}$ showed almost half of magnetstriction and $70 \%$ of voltage generation comparing to the Galfenol standard. Moreover, homogeneity of chemical composition of $\mathrm{Fe}-\mathrm{Al}$ alloy grown by the $\mu$-PD method is superior to $\mathrm{Fe}-\mathrm{Ga}$ alloy grown by $\mu-\mathrm{PD}$ and $\mathrm{Cz}$ methods. $\mathrm{Fe}-\mathrm{Al}$ have better mass productivity and can be one of promising material for vibration energy harvester. 


\section{Acknowledgments}

This work was supported by KAKENHI, Grants-inAid for Scientific Research 17H06159.

\section{References}

[1] T. Ueno, S. Yamada, IEEE Trans. Magn. 47, 2407 (2011).

[2] B. Rezaeealam, T. Ueno, S. Yamada, IEEE Trans. Magn. 48, 3977 (2012)

[3] R. Grossinger, R. Sato Turtelli, N. Mehmood, IEEE Trans. Magn. 44,3001 (2008).

[4] S. Asano, S. Fujieda, S. Hashi, K. Ishiyama, T. Fukuda, S. Suzuki, IEEE Magn. Lett. 8, 1 (2016).

[5] M. Ito, K. Kamada, A. Yoshikawa, T. Kawamata, S. Fujieda, S. Suzuki, T. Minamitani, T. Ueno, J. Alloys Compd. 731, 898 (2017).

[6] A.E. Clark, J.B. Restorff, M. Wun-Fogle, D. Wu, T.A. Lograsso, DOI: 10.1063/1.2831360, Appl. Phys. 103 (2008)07B310.

[7] R. Grossinger, R. Sato Turtelli, N. Mehmood, IOP Conf. Series: Materials Science and Engineering 60, 012002 (2014).
[8] A.E. Clark, J.B. Restorff, M. Wun-Fogle, T.A. Lograsso, D.L. Schlagel, IEEE Trans. Magn. 36, 3238 (2000).

[9] J.B. Restorff, M. Wun-Fogle, A.E. Clark, T.A. Lograsso, A.R. Ross, D.L. Schlagel, J. Appl. Phys. 91, 8225 (2002).

[10] E.M. Summers, T.A. Lograsso, J.D. Snodgrass, J. Slaughter, Proceedings of SPIE 5387, 448 (2004).

[11] S. Fujieda, S. Suzuki, A. Minato, T. Fukuda, T. Ueno, IEEE Trans. Magn. 50, 2505204 (2014).

[12] A. Yoshikawa, V.I. Chani, MRS Bulletin 34, 266 (2009).

[13] K.Kamada, R. Murakami, V.V. Kochurikhin, G. Luidmila, K.J. Kim, Y. Shoji, A. Yamaji, S. Kurosawa, Y. Ohashi, Y. Yokota, A. Yoshikawaa, J. Cryst. Growth 492, 45 (2018).

[14] T. Nihei, Y. Yokota, M. Arakawa, Y. Ohashi, S. Kurosawa, K. Kamada, V. Chani, A. Yoshikawa, J. Cryst. Growth 468, 403 (2017). 